\title{
Review
}

\section{Neuroprotection through Stimulation of Mitochondrial Antioxidant Protein Expression}

\author{
Tiffany Greco ${ }^{\mathrm{a}, \mathrm{b}}$ and Gary Fiskum ${ }^{\mathrm{a}, *}$ \\ ${ }^{\mathrm{a}}$ Department of Anesthesiology and the Shock Trauma and Anesthesiology Research Center, University of \\ Maryland School of Medicine, Baltimore, MD, USA \\ ${ }^{\mathrm{b}}$ Graduate Program in Life Sciences Molecular Medicine Program, University of Maryland School of Medicine, \\ Baltimore, MD, USA
}

\begin{abstract}
Oxidative stress and loss of cellular $\mathrm{Ca}^{2+}$ homeostasis are closely linked and are common denominators in the pathophysiology of many neurodegenerative diseases and acute disorders of the nervous system. Mitochondria are major targets of oxidative stress and abnormal intracellular $\mathrm{Ca}^{2+}$, as both can cause bioenergetic failure through synergistic activation of the mitochondrial inner membrane permeability transition pore. Opening of this molecularly ill-defined pore causes both collapse of the membrane potential, which drives oxidative phosphorylation, and release of small metabolites, including pyridine nucleotides and glutathione, which are necessary for energy metabolism and defense against oxidative stress. Expression of genes coding for many antioxidant defense proteins is regulated by the Nrf2 transcriptional activating factor. Translocation of this protein from the cytosol to the nucleus is stimulated by oxidative stress and by specific agents that either react with cysteine sulfhydryl groups present on the protein KEAP1, that normally binds and restricts Nrf2 translocation, or that stimulate serine phosphorylation of Nrf2. Recent evidence indicates that mitochondria are a target of the cytoprotective gene expression induced by Nrf2 and that this pathway can increase resistance to redox-regulated opening of the permeability transition pore. Pharmacologic stimulation of the Nrf2 system and its protection against mitochondrial bioenergetic dysfunction may therefore constitute a powerful mechanism for both pre-conditioning against neurodegeneration and for post-conditioning against neural cell death associated with acute neurologic injury.
\end{abstract}

Keywords: Antioxidant, bioenergetics, calcium, cerebral ischemia, neurodegeneration, Nrf2, oxidative stress, permeability transition pore

\section{OXIDATIVE STRESS AND MITOCHONDRIAL DYSFUNCTION IN NEURODEGENERATION}

Figure 1 summarizes many of the known targets of reactive oxygen and nitrogen species (ROS/RNS) that

${ }^{*}$ Correspondence to: Dr. Gary Fiskum, University of Maryland School of Medicine, Department of Anesthesiology, 685 W. Baltimore Street, Baltimore, Maryland 21201, USA. Tel.: +1 410706 4711; Fax: +1 410706 2550; E-mail: gfiskum@anes.umm.edu. are located at mitochondria or that are extramitochondrial but have strong secondary effects on mitochondrial bioenergetic or apoptotic activities. The most acute influence of ROS/RNS on mitochondria is mediated by oxidative modifications of proteins present in the electron transport chain (ETC) [1,2], other metabolic proteins, e.g., pyruvate dehydrogenase aconitase and $\alpha$-ketogluatarate dehydrogenase [3-5], and the inner membrane permeability transition pore (PTP) $[6,7]$. Oxidation of cardiolipin, a phospholipid primarily lo- 


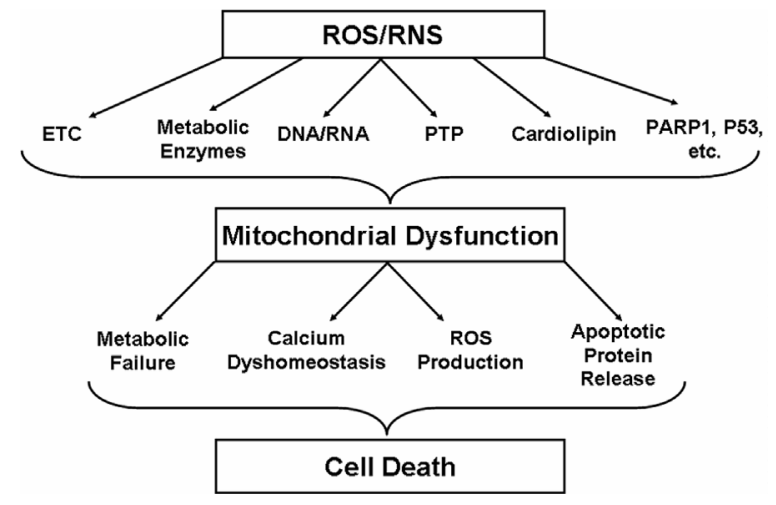

Fig. 1. Mitochondrial targets of reactive oxygen and nitrogen species and their effects on mitochondrial bioenergetic and apoptotic activities.

cated in the mitochondrial inner membrane, can also cause rapid mitochondrial functional alterations, including stimulated release of mitochondrial apoptotic proteins $[8,9]$. Oxidation of mitochondrial mRNA can limit the expression of any one of the 13 polypeptides coded for by the mitochondrial genome, resulting in delayed bioenergetic impairment [10]. Metabolic depression and increased ROS production by the ETC also occurs in response to mitochondrial DNA oxidation, which is associated with neurodegenerative disorders and normal aging [11]. Finally, ROS/RNS are known to stimulate the activity of poly-ADP ribose polymerase 1 (PARP1) and the expression of P53, which in turn can cause release of mitochondrial apoptotic proteins and poly-ADP ribosylation of mitochondrial proteins [1215].

Several lines of evidence support the hypothesis that oxidative stress and associated mitochondrial bioenergetic dysfunction and activation of apoptosis are common etiological factors in many neurodegenerative diseases and acute disorders of the central nervous system (CNS) [16]. Descriptive experimental support includes the findings that mitochondrial morphology is altered, that metabolic activities are depressed, and that mitochondrial pro-apoptotic proteins are released to the cytosol prior to the death of neurons and other brain cells in both animal and cell culture models of neurodegeneration [17-22]. Biochemical markers of oxidative stress often exhibit close tempero-spatial relationships with these indicators of mitochondrial dysfunction $[10$, 23-25]. Moreover, agents or conditions that either decrease the production of reactive oxygen or nitrogen species (ROS/RNS) or increase their detoxification both ameliorate the mitochondrial functional anomalies and provide protection against subsequent cell death and neurologic impairment. Such agents include novel antioxidants that are both lipophilic and that have a net positive charge, enabling them to be selectively accumulated within energized mitochondria, which possess a negative inside membrane potential $[26,27]$.

One fundamental environmental factor that influences mitochondrial oxidative stress is oxygen. For example, hyperoxic reperfusion immediately after global cerebral ischemia increases oxidative protein and lipid oxidation, impairs mitochondrial respiration and cerebral energy metabolism, exacerbates delayed neuronal death, and worsens neurologic outcome [28-30]. In contrast to interventions utilizing exogenous antioxidants, avoiding unnecessary hyperoxia under conditions where cells are particularly vulnerable to oxidative stress likely improves outcome by reducing the production of ROS/RNS, due to simply restricting the concentration of $\mathrm{O}_{2}$ available for reactions that produce superoxide and nitric oxide [31]. Remarkably, hypoxia can also promote mitochondrial oxidative stress when the concentration of $\mathrm{O}_{2}$ is below the level necessary for sustaining normal respiration. Hypoxic oxidative stress is promoted by nitric oxide, which competes with $\mathrm{O}_{2}$ at cytochrome oxidase, the terminal reaction of the ETC. This form of respiratory inhibition causes a reduced shift in the oxidation/reduction state of ETC redox centers capable of reducing $\mathrm{O}_{2}$ to superoxide, increasing the production of this free radical and its metabolites, resulting in oxidative stress, even at very low $\mathrm{O}_{2}$ levels [32].

In addition to the correlative evidence provided by comparisons between markers of oxidative stress, mitochondrial dysfunction, and cell death or neurologic outcome, genetic manipulation of proteins involved in both the production and detoxification of ROS/RNS and important mitochondrial targets of oxidative stress has provided independent evidence for their pathophysiological importance. For instance, overexpression of certain mitochondrial uncoupling proteins appears to both reduce production of ROS and provide neuroprotection [33-36]; however, a direct link between respiratory uncoupling and these two activities has not been proven conclusively [37]. Stronger molecular mechanistic evidence comes from knockouts and overexpression of the mitochondria-specific manganese superoxide dismutase (MnSOD). Genetically modified mice that overexpress or are deficient in MnSOD display resistance or vulnerability, respectively, to both oxidative stress and neurodegeneration in models of Alzheimer's and Parkinson's diseases and stroke [38-41]. An example of a critically important mitochondrial target of ox- 
idative stress is the inner membrane permeability transition pore [42], as discussed in more detail below. Genetically modified mice that do not express cyclophilin $\mathrm{D}(\mathrm{CyD})$, a protein that promotes activation of the PTP, exhibit attenuated brain injury in models of stroke and multiple sclerosis $[43,44]$. Moreover, cells from CyD knockout mice are much more resistant to death induced by hydrogen peroxide than those from wild-type animals, indicating a role for CyD and the PTP in cell death induced by oxidative stress [43].

Examples of how experimental manipulation of genes that code for antioxidant enzymes or mitochondrial targets of oxidative stress can influence neurodegeneration are surpassed by the number of antioxidant and other cytoprotective genes that are both induced by endogenous oxidative stress and by exposure of cells or animals to certain drugs and environmental conditions. A master regulator of this system is the transcriptional activating factor, Nrf2.

\section{THE Nrf2/ARE SYSTEM}

\section{Nrf2/ARE regulation}

Nuclear factor erythroid 2-related factor 2 (Nrf2) is a nuclear transcription factor that belongs to the "cap"n collar" family that share a conserved basic leucine zipper (bZip) structure [45]. Under normal conditions, $\mathrm{Nrf} 2$ is kept inactive by being bound to Kelch like ECHassociated protein (KEAP1). KEAP1 is localized in the cytosol where it is bound to the actin cytoskeleton and targets Nrf2 for proteosomal degradation by being a Cul3-based E3 ligase adaptor. In the presence of ROS/RNS or certain electrophilic organic compounds, specific cysteine residues on KEAP1 are oxidized, causing a conformational change in KEAP1 and the release of Nrf2 into the cytosol. Oxidative stress also activates specific protein kinases, e.g., protein kinase c (PKC), which serine phosphorylate Nrf2, facilitating dissociation from KEAP1 and enabling transport of Nrf2 into the nucleus [45]. Electrophiles can also oxidize critical cysteine sulfhydryl groups present on Nrf2, masking the nuclear export signal sequence and allowing Nrf2 to remain within the nucleus long enough to activate gene transcription [46]. Within the nucleus, Nrf 2 forms heterodimers with sMAF proteins that also stabilize nuclear retention. These heterodimers bind to antioxidant response element (ARE) sequences and recruit transcriptional enzymes and other proteins to these locations [47]. Since an ARE sequence is locat- ed proximal to the Nrf2 gene, Nrf2 activation acts in a positive, feed-forward manner [48]. To prevent continuous transcriptional activation of this and many other genes, nuclear tyrosine kinases phosphorylate Nrf2, stimulating its translocation out of the nucleus back to the cytosol [49].

\section{Transcriptional regulation by $\mathrm{Nrf} 2$}

While Nrf2 is widely known for its regulation of phase II detoxification enzymes, it has transcriptional control over many genes that include an ARE sequence in their promoter region. Some of the commonly known genes it regulates include $\mathrm{NAD}(\mathrm{P}) \mathrm{H}$ :quinone oxidoreductase 1 (NQO1), heme oxygenase 1 (HO-1), glutathione S-transferases (GST), glutathione synthetic enzymes, antioxidant enzymes, and NADPH regenerating enzymes, e.g., glucose-6-phosphate dehydrogenase and malic enzyme [50]. In various proteomic studies, Nrf2 has been shown to control genes involved in immunity, membrane transport, cell adhesion, cell cycle, and energy metabolism, among others [51]. Numerous kinases and phosphatases are also under the regulation of Nrf2, including mitogen activated protein kinase (MAPK), serine kinases, and tyrosine phosphatases [51]. Several Nrf2-regulated genes code for important regulators of cellular energy metabolism, including the mitochondrial enzymes pyruvate dehydrogenase lipoamide $\beta$ and pyruvate dehydrogenase kinase. Nrf2 also exerts control over aquaporin, multiple classes of ATPases, chloride, potassium, and calcium and folate channels $[50,51]$.

\section{INDUCTION OF THE Nrf2/ARE PATHWAY}

\section{Pharmacologic activation of the Nrf2/ARE pathway}

This field of research was spawned by the observation that when mice were fed chow containing both carcinogens plus the electrophilic preservative butylated hydroxyanisole (BHA), they were protected from stomach cancer that was induced by the carcinogens in the absence of BHA [52]. Subsequently, it was determined that this inducible xenobiotic response was mediated by phase II detoxification enzymes and that the Nrf2/ARE pathway was responsible for inducing the expression of genes coding for these proteins [48]. This discovery led to the search for and identification of compounds that could safely activate the Nrf2/ARE pathway of gene expression [53]. 


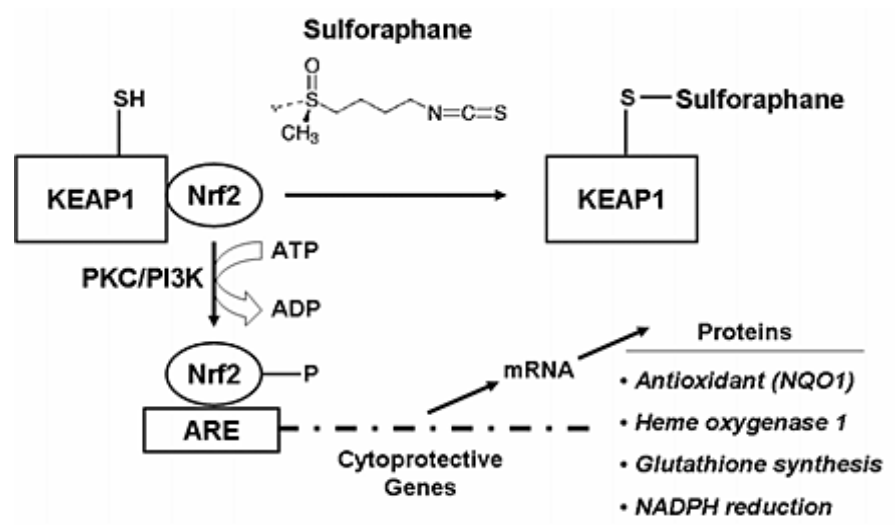

Fig. 2. Activation of Nrf2/Antioxidant Response Element (ARE) pathway of gene expression. Two primary mechanisms of activation include oxidation of specific cysteine sulfhydryl groups on KEAP1, e.g., by reaction with sulforaphane, and serine phosphorylation of Nrf2 by enzymes including protein kinase $\mathrm{c}(\mathrm{PKC})$ and phosphatidlyinositol 3-kinase (PI3K).

\section{Electrophilic activation}

Sulforaphane is a compound derived from a glucosinolate found in cruciferous vegetables such as broccoli and kale in the Brassica genus. When these foods are consumed, the salivary enzyme myrosinase converts the inactive glucosinolate, glucoraphanin, into its active isothiocyanate form, sulforaphane (see Fig. 2). The central carbon of its electrophilic cyanate group,$\mathrm{N}=\mathrm{C}=\mathrm{S}$, reacts with nitrogen, sulfur, and oxygen based nucleophilies [54]. Following rapid uptake of sulforaphane into tissues and cells, this cyanate group reacts rapidly with three critical cysteines, $\mathrm{C}^{151} \mathrm{C}^{273}$ $\mathrm{C}^{288}$, on KEAP1, causing a conformational change that reduces its affinity for Nrf2. Nrf2 is released into the cytoplasm, enters the nucleus, and activates ARE-driven genes [55]. While traditional focus has been on KEAP1 as the redox sensor mediating Nrf2 translocation, Nrf2 itself may be the key redox sensor and thus control its own nuclear translocation. Central to this model is a single cysteine, $\mathrm{C}^{183}$, present within the nuclear export signal sequence located in the transactivation domain $\left(\mathrm{NES}_{T A}\right)$ of Nrf2. Experiments using expression of a GFAP-tagged, truncated Nrf2 containing the $\mathrm{NES}_{T A}$ demonstrate dose-dependent translocation of the protein by SFP. When this cysteine is mutated to an alanine, the protein is unable to translocate to the nucleus, thus identifying $\mathrm{C}^{183}$ as a critical redox sensor on Nrf2. In summary, SFP oxidatively modifies KEAP1 and reduces its affinity for Nrf2. Nrf2 released into the cytosol is then oxidized by sulforaphane, promoting its entry into the nucleus [46]. Other electrophilic compounds that appear to act by the same mechanism as that of sulforaphane include carnosic acid [56] and curcumin [57].

\section{Activation of Nrf2 by phosphorylation events}

In addition to redox modulation of KEAP1 and Nrf2, phosphorylation of Nrf2 facilitates its stabilization and translocation into the nucleus [45]. Treatment of various cell lines with either tert-butyl hydroquinone (tBHQ) [58] or plumbagin [59], a pigment extracted from the Plumbaginaceae family of flowering plant that contains anti-microbial properties, results in activation of the PI3K/AKT signaling cascade, causing phosphorylation and activation of Nrf2 [59]. If PI3K inhibitors wortmannin or LY294002 are present, Nrf2 translocation is abrogated $[59,60]$. PKC mediates phosphorylation of Nrf2 at serine 40 [61]. While phosphorylation of serine 40 is not required for translocation of Nrf2 into the nucleus, it plays a critical yet still undefined role in the interaction between KEAP1 and Nrf2 [61]. One model states that phosphorylation of Nrf2 is absolutely required for release of Nrf2 from KEAP1 [61]. An alternative model contends that phosphorylated free Nrf2 is unable to bind KEAP1 therefore stabilizing Nrf2 and contributing to the increase of free Nrf2 in the cytoplasm [48,62]. Beyond cytoplasmic stabilization of Nrf2, PKC contributes to Nrf2 nuclear retention by phosphorylating GSK $3 \beta$ thus inhibiting the GSK $3 \beta /$ Fyn signaling cascade, which is responsible for nuclear export of Nrf2 [62].

\section{ROLE OF Nrf2 IN NEUROPROTECTION}

\section{Acute CNS injury}

Several different animal models of acute brain injury have demonstrated neuroprotection by pharmacologic 
activation of the Nrf2/ARE pathway of gene expression. In a rat model of intracerebral hemorrhage (ICH) using extravasated blood, post-hemorrhagic administration of sulforaphane is followed by translocation of Nrf2 to the nucleus, an increase in mRNA levels for superoxide dismutase 1 (SOD1), GST and NQO1, and an improvement in neurologic outcome [63]. Using the same ICH model in mice, post-treatment with sulforaphane resulted in improvements in wild-type animal's neurological deficit score while Nrf2 knockout mice had a worse score and sulforphane no longer had any neuroprotective affects [63]. In a separate ICH model where collagenase is used, Nrf2 knockout mice exhibit increased brain injury, worse neurological outcome, and increased evidence of oxidative stress, compared to Nrf2 wild-type mice [64]. In a rat focal ischemic stroke model, sulforaphane posttreatment reduces brain infarct volume and increases the levels of both HO-1 mRNA and protein [65]. Nrf2 knockout mice display an increase in infarct volume and worsened neurologic outcome, compared to wild-type mice $[66,67]$. Neuroprotection following ischemic stroke has also been demonstrated by administration of carnosic acid, which also activates the Nrf2 pathway [56].

Intraperitoneal administration of sulforaphane to rats or mice after traumatic brain injury results in an increase in mRNAs for various phase II response enzymes and reduced impairment of memory and cognition [68-70]. Importantly, Nrf2 knockout mice do not demonstrate improved outcome when treated with sulforaphane [70]. Preliminary results also indicate neuroprotection by sulforaphane post-treatment in a large animal model of acute brain injury. Specifically, intravenous administration of sulforaphane at $1 \mathrm{mg} / \mathrm{kg}$ to adult beagles at $30 \mathrm{~min}$ after cardiac arrest and resuscitation reduces hippocampal neuronal death and improves neurologic outcome [71]. In vitro experiments suggest that the neuroprotective effects of sulforaphane may target both neurons and glia. Pre- or post-treatment of cortical astrocytes or hippocampal neurons with sulforaphane increases Nrf2-regulated expression of NQO1, HO-1, among other genes, and reduced delayed cell death following transient $\mathrm{O}_{2}$ and glucose deprivation [72,73]. In an organotypic culture model of spinal cord injury, results indicate that pharmacologic activation of the Nrf2 pathway prevents motor neuron cell death, upregulates Nrf2 and HO-1 mRNA levels, reduces toxic extracellular levels of glutamate, and preserves mitochondrial ultrastructure [74].

The success of this approach in various in vivo and in vitro models is likely due to the multiple antioxidant and other cytoprotective genes that are induced. This strategy thus represents a novel "combination therapy" approach and may therefore be more effective or broadly applicable than the use of antioxidant drugs that normally target only one or a few specific ROS or RNS. Taken together, these findings demonstrating neuroprotection by sulforaphane post-treatment as well as pre-treatment in different models of acute CNS injury provide optimism that pharmacologic activation of the Nrf2/ARE system will eventually be translated to effective clinical therapeutic interventions.

\section{Neurodegenerative diseases}

Neuroprotection through upregulation of the Nrf2 pathway of cytoprotective gene expression is also applicable to neurodegenerative diseases. Alzheimer's disease $(\mathrm{AD})$ is characterized histologically by amyloid$\beta(\mathrm{A} \beta)$ plaques and neurofibrillary tangles in various brain locations. In an in vitro model of AD cytopathology, treatment of differentiated NT2N neurons with 4-hydroxynonenal induces formation of $\mathrm{A} \beta$ tangles. When these cultures are pre-treated with the pro-oxdiant, tert-butyl hydroquinone, Nrf2 is activated, followed by decreased $\mathrm{A} \beta$ formation and caspase 3 activation [75]. In a transgenic mouse AD model expressing mutated human amyloid- $\beta$ protein precursor and presenilin 1 genes, intra-hippocampal injections of lentiviruses containing the Nrf2 gene result in elevated HO-1 gene expression and improved spatial learning memory [76]. In a mouse cytotoxin (malonate) model of Huntington's disease, neuroprotection is observed by intrastriatal implantation of astrocytes with activated Nrf2-mediated gene expression [77]. Pretreatment of either dopaminergic cell lines or nigrostriatal co-cultures with sulforaphane provides neuroprotection against Parkinson's disease neurotoxins, e.g., 6-hydroxydopamine [78,79]. Mechanisms of neuroprotection in these models may include the increased expression of NQO1, which prevents ROS production that is catalyzed by the semiquinone fraction of the increased pool of quinones generated by aberrant dopamine metabolism, and increased levels of glutathione GSH, which detoxify peroxides and protect against oxidation of protein sulfhydryl groups [79]. In a MPTP mouse model of Parkinson's disease, overexpression of Nrf2 in astrocytes prevents neuronal death and reduces inflammation [80]. In a mouse model of amyotrophic lateral sclerosis, overexpression of Nrf2 in astrocytes improves neuronal survival and slows disease progression [81]. Additional evidence for the im- 
portance of Nrf2 in maintaining resistance to neurodegeneration comes from models where outcome is worsened by knockout of Nrf2 gene expression, e.g., in the malonate model of Huntington's disease [77], the MPTP model of Parkinson's disease [80,82], and in a kainate-induced status epilepticus mouse model [83]. The experimental evidence therefore strongly supports an important role of $\mathrm{Nrf} 2$ and its regulation of cytoprotective gene expression in both resistance to neurological disorders and in response to exogenous agents that can protect against or slow the progression of neurodegenerative diseases.

\section{Nrf2-REGULATED ANTIOXIDANT DEFENSE SYSTEMS}

All tissues possess redundant antioxidant defense systems for detoxifying the ROS and RNS that are constantly present and that play important roles as intracellular and transcellular regulatory signals. Considerable effort has been made to characterize these systems in the brain, knowing that oxidative stress plays a major role in most forms of both acute CNS injury and in chronic neurodegenerative disorders. It was recognized early during these investigations that the gene expression for many of the antioxidant associated proteins is upregulated in response to oxidative and other forms of stress. For instance, HO-1 and SOD2 gene induction occurs rapidly following focal cerebral ischemia $[84,85]$. These observations taken together with those demonstrating stress-induced increased expression of anti-apoptotic genes, e.g., Bcl-2, led to the concept of genomic preconditioning against brain injury, using levels of stress that are sufficient to activate cytoprotective gene expression but that are also below the threshold for inducing significant cell dysfunction or death.

It now appears that at least some if not many of the genes that are induced in the brain following both toxic and sub-toxic levels of stress may be activated via the Nrf2/ARE system [61]. Products of these genes include SOD1 (cytosolic), SOD2 (mitochondrial), and SOD3 (extracellular) [86,87] and the peroxide detoxifying enzymes glutathione peroxidase [88] and catalase [89,90]. Nrf2 also mediates induction of glutamate-cysteine ligase catalytic subunit (GCLC) and glutamate-cysteine ligase, modifier subunit (GCLM), both of which are necessary for glutathione biosynthesis [91]. NAD(P)H is critical to antioxidant detoxification as it provides the reducing power needed to keep glutathione reduced.
Malic enzyme (ME) and hexose monophosphate shunt dehydrogenases are the primary producers of cytosolic NADPH and are induced by Nrf2 in the small intestine but their induction has yet to be reported for brain [50]. Another gene subject to Nrf2 control is HO-1, which catalyses the catabolism of heme to carbon monoxide (CO), biliverdin and iron [92]. Upregulation of HO-1 [65] leads to increased bilirubin levels, a product of oxidized biliverdin, which is a potent antioxidant. The $\mathrm{CO}$ created by $\mathrm{HO}-1$ indirectly activates the AKT signaling pathway that potentiates Nrf 2 cytoprotection by at least two mechanisms: First, it prevents the phosphorylation of GSK-3 $\beta$, promoting nuclear retention of $\mathrm{Nrf} 2$ and therefore transcription of Nrf2 driven genes [92]. Secondly, it promotes the translocation of nuclear respiratory factor 1 (Nrf1) to the nucleus which in turn stimulates the transcription and translation of Tfam, that stimulates transcription replication of the mitochondrial genome, promoting mitochondrial biogenesis [92]. Finally, NQO1, which is perhaps the most commonly used marker of Nrf2 activated gene expression, directly reduces semiquinones to hydroquinones, which inhibits superoxide production catalyzed by semiquinone radicals and provides the fully reduced quinones that function as free radical scavengers [93].

\section{MITOCHONDRIAL ANTIOXIDANT DEFENSES AND POTENTIAL REGULATION BY Nrf2}

The majority of ROS that are produced the in the mitochondria are a byproduct of the respiratory chain and specific dehydrogenases, e.g., $\alpha$-ketoglutarate dehydrogenase [94-99]. The primary species generated is the superoxide radical $\mathrm{O}_{2}^{-}$. As shown in Fig. 3, under normal conditions, the $\mathrm{O}_{2}^{-}$is converted to $\mathrm{H}_{2} \mathrm{O}_{2}$ by SOD2. Another important source of mitochondrial $\mathrm{H}_{2} \mathrm{O}_{2}$ is monoamine oxidase [100,101]. $\mathrm{H}_{2} \mathrm{O}_{2}$ is further converted to $\mathrm{H}_{2} \mathrm{O}$, by catalase, and glutathione or thioredoxin peroxidases at the expense of either reduced glutathione $(\mathrm{GSH})$ or reduced thioredoxin (TrxSH). GSSG or TrxS ${ }^{-}$are reduced by their respective glutathione or thioredoxin reductases, using NADPH as the electron donor [102]. The NADPH pool in the mitochondria is maintained mostly through the activities of several enzymes, including transhydrogenase, mitochondrial malic enzyme (ME3), and $\mathrm{NADP}^{+}$-selective isocitrate and glutamate dehydrogenases. 


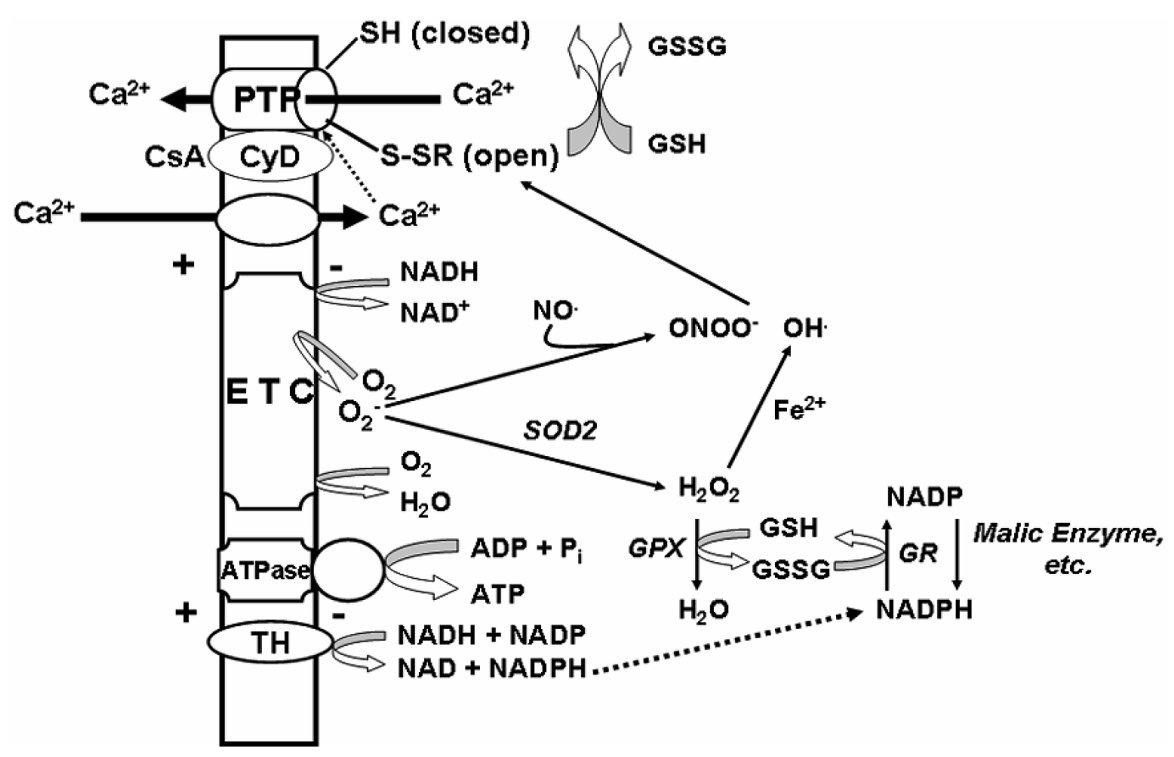

Fig. 3. Redox regulation of the mitochondrial permeability transition pore (PTP). Opening of the PTP is promoted by elevated intramitochondrial $\mathrm{Ca}^{2+}$ and by conditions that promote protein sulfhydryl oxidation, including the presence of peroxynitrite $\left(\mathrm{ONOO}^{-}\right)$and hydroxyl radical $(\mathrm{OH} \cdot)$ and a relatively low ratio of reduced to oxidized glutathione (GSH/GSSG). The glutathione redox state is determined by the balance between its reduction by the NADPH-dependent glutathione reductase (GR) and its oxidation, e.g., by glutathione peroxidase (GPX). Intramitochondrial $\mathrm{NADP}^{+}$is reduced to form NADPH by several enzymes including the inner membrane potential-driven transhydrogenase (TH) and cell-type selective isoenzymes, including malic enzyme 3 and $\mathrm{NADP}^{+}$-dependent isocitrate dehydrogenase glutamate dehydrogenase. The presence of elevated peroxides, including hydrogen peroxide $\left(\mathrm{H}_{2} \mathrm{O}_{2}\right)$ generated e.g., by mitochondrial superoxide dismutase (SOD2) promote PTP opening by shifting the mitochondrial redox state, including that of glutathione, to a more oxidized level. PTP opening is subject to pharmacological inhibition, e.g., by the interaction of cyclosporin A with cyclophilin D, a protein that regulates but is not equivalent to the PTP.

Oxidative stress occurs within the mitochondria, as it does in other cellular locations, when the rate of ROS production and ROS detoxification are unbalanced. Increased production of toxic superoxide and consequently hydrogen peroxide can exceed their rate of detoxification, resulting in toxic metabolites, e.g., peroxynitrite and hydroxyl radical, that can cause mitochondrial dysfunction through the oxidation of various proteins, lipids and nucleic acids as described earlier (see Fig. 1). However, growing evidence suggests that protection against ROS accumulation can occur through increased expression of mitochondrial antioxidant enzymes, e.g., SOD2, or proteins responsible for the biosynthesis of glutathione and for the reduction of $\mathrm{NADP}^{+}$. Levels of SOD2 and mitochondrial glutathione peroxidase and reductase and glutathione are elevated by treatment of aortic smooth muscle cells and cardiac myocytes with sulforaphane [103] or dithiolethione, another organosulfur compound [104]. While these effects have not yet been reported for mitochondria present within neurons or the CNS, preliminary results from our lab support this hypothesis and demonstrate that mitochondria from the brains of rats treated with sulforaphane are resistant to t-butyl hydroperoxide-induced opening of the PTP [71]. Possible explanations for this indirect effect of sulforaphane include increased expression of mitochondrial enzymes that reduce $\mathrm{NADP}^{+}$to NADPH [105] and increased expression of the anti-apoptotic mitochondrial protein, Bcl-2. Cardiac Bcl-2 levels are elevated in rats maintained on a high broccoli diet [106]. Moreover, we have shown that mitochondria within Bcl-2 overexpressing neural cell lines are resistant to PTP opening [107]. Irrespective of the mechanism by which sulforaphane inhibits PTP opening, this effect could contribute to the cytoprotective effects of this drug and others that act through the Nrf2/ARE system, since PTP opening contributes to bioenergetic failure and cell death in many models of acute and chronic neurodegeneration and in cell death that occurs in the cardiovascular, renal, and other systems [108-110].

\section{SUMMARY}

Mitochondria are both important producers of ROS/RNS and very sensitive to damage caused by these molecules either directly or through the oxidative stress 
associated with their metabolism. Exogenous antioxidants, including those that are targeted to mitochondria, can increase mitochondrial resistance to oxidative damage and consequently provide neuroprotection for neurologic disorders and diseases. Another approach, which is also showing great promise, is pharmacologic activation of endogenous antioxidant gene expression, including that which is controlled by the Nrf2/ARE system. Preliminary evidence indicates that this strategy can protect mitochondria against oxidative damage and bioenergetic dysfunction; however, the molecular mechanisms responsible for this defense have yet to be elucidated.

\section{ACKNOWLEDGMENTS}

The authors were supported by NIH grants R01NS34 152 and P01HD16596 and the US Army grant W81XWH-07-2-0118 during the writing of this review.

Authors' disclosures available online (http://www.jalz.com/disclosures/view.php?id=428).

\section{REFERENCES}

[1] Keeney PM, Xie J, Capaldi RA, Bennett JP, Jr. (2006) Parkinson's disease brain mitochondrial complex I has oxidatively damaged subunits and is functionally impaired and misassembled. J Neurosci 26, 5256-5264

[2] Brown GC, Borutaite V (2004) Inhibition of mitochondrial respiratory complex I by nitric oxide, peroxynitrite and Snitrosothiols. Biochim Biophys Acta 1658, 44-49.

[3] Richards EM, Rosenthal RE, Kristian T, Fiskum (2006) Postischemic hyperoxia reduces hippocampal pyruvate dehydrogenase activity. Free Radic Biol Med 40, 1960-1970.

[4] Poon HF, Shepherd HM, Reed TT, Calabrese V, Stella AM, Pennisi G, Cai J, Pierce WM, Klein JB, Butterfield DA (2006) Proteomics analysis provides insight into caloric restriction mediated oxidation and expression of brain proteins associated with age-related impaired cellular processes: Mitochondrial dysfunction, glutamate dysregulation and impaired protein synthesis. Neurobiol Aging 27, 1020-1034.

[5] Park LC, Zhang H, Sheu KF, Calingasan NY, Kristal BS, Lindsay JG, Gibson GE (1999) Metabolic impairment induces oxidative stress, compromises inflammatory responses, and inactivates a key mitochondrial enzyme in microglia. J Neurochem 72, 1948-1958.

[6] Battaglia V, Grancara S, Satriano J, Saccoccio S, Agostinelli E, Toninello A (2010) Agmatine prevents the $\mathrm{Ca}(2+)$ dependent induction of permeability transition in rat brain mitochondria. Amino Acids 38, 431-437.

[7] Petronilli V, Costantini P, Scorrano L, Colonna R, Passamonti S, Bernardi P (1994) The voltage sensor of the mitochondrial permeability transition pore is tuned by the oxidationreduction state of vicinal thiols. Increase of the gating potential by oxidants and its reversal by reducing agents. $J$ Biol Chem 269, 16638-16642.
[8] Ott M, Gogvadze V, Orrenius S, Zhivotovsky B (2007) Mitochondria, oxidative stress and cell death. Apoptosis 12, 913922.

[9] Bayir H, Fadeel B, Palladino MJ, Witasp E, Kurnikov IV, Tyurina YY, Tyurin VA, Amoscato AA, Jiang J, Kochanek PM, DeKosky ST, Greenberger JS, Shvedova AA, Kagan VE (2006) Apoptotic interactions of cytochrome c: Redox flirting with anionic phospholipids within and outside of mitochondria. Biochim Biophys Acta 1757, 648-659.

[10] Nunomura A, Hofer T, Moreira PI, Castellani RJ, Smith MA, Perry G (2009) RNA oxidation in Alzheimer disease and related neurodegenerative disorders. Acta Neuropathol 118, 151-166.

[11] Lovell MA, Markesbery WR (2007) Oxidative DNA damage in mild cognitive impairment and late-stage Alzheimer's disease. Nucleic Acids Res 35, 7497-7504.

[12] Wang Y, Dawson VL, Dawson TM (2009) Poly(ADP-ribose) signals to mitochondrial AIF: a key event in parthanatos. Exp Neurol 218, 193-202.

[13] Mattson MP (2003) Excitotoxic and excitoprotective mechanisms: abundant targets for the prevention and treatment of neurodegenerative disorders. Neuromolecular Med 3, 65-94.

[14] Chipuk JE, Kuwana T, Bouchier-Hayes L, Droin NM, Newmeyer DD, Schuler M, Green DR (2004) Direct activation of Bax by 533 mediates mitochondrial membrane permeabilization and apoptosis. Science 303, 1010-1014.

[15] Lai Y, Chen Y, Watkins SC, Nathaniel PD, Guo F, Kochanek PM, Jenkins LW, Szabo C, Clark RS (2008) Identification of poly-ADP-ribosylated mitochondrial proteins after traumatic brain injury. $J$ Neurochem 104, 1700-1711.

[16] Lin MT, Beal MF (2006) Mitochondrial dysfunction and oxidative stress in neurodegenerative diseases. Nature $\mathbf{4 4 3}$, 787-795.

[17] Moreira PI, Zhu X, Wang X, Lee HG, Nunomura A, Petersen RB, Perry G, Smith MA (2010) Mitochondria: a therapeutic target in neurodegeneration. Biochim Biophys Acta 1802, 212-220.

[18] Yap LP, Garcia JV, Han D, Cadenas E (2009) The energyredox axis in aging and age-related neurodegeneration. $A d v$ Drug Deliv Rev 61, 1283-1298.

[19] Swerdlow RH (2009) The neurodegenerative mitochondriopathies. J Alzheimers Dis 17, 737-751.

[20] Gogvadze V, Orrenius S, Zhivotovsky B (2009) Mitochondria as targets for chemotherapy. Apoptosis 14, 624-640.

[21] Knott AB, Bossy-Wetzel E (2008) Impairing the mitochondrial fission and fusion balance: a new mechanism of neurodegeneration.Ann N Y Acad Sci 1147, 283-292.

[22] de la Monte SM, Wands JR (2006) Molecular indices of oxidative stress and mitochondrial dysfunction occur early and often progress with severity of Alzheimer's disease. $J$ Alzheimers Dis 9,167-181.

[23] Niizuma K, Endo H, Chan PH (2009) Oxidative stress and mitochondrial dysfunction as determinants of ischemic neuronal death and survival. $J$ Neurochem 109,133-138.

[24] Pope S, Land JM, Heales SJ (2008) Oxidative stress and mitochondrial dysfunction in neurodegeneration; cardiolipin a critical target? Biochim Biophys Acta 1777, 794-799.

[25] Kauppinen TM, Swanson RA (2007) The role of poly (ADPribose) polymerase-1 in CNS disease. Neuroscience $\mathbf{4 5}$, 1267-1272.

[26] Murphy MP (2008) Targeting lipophilic cations to mitochondria. Biochim Biophys Acta 1777, 1028-1031.

[27] Sheu SS, Nauduri D, Anders MW (2006) Targeting antioxidants to mitochondria: a new therapeutic direction. Biochim 
Biophys Acta 1762, 256-265.

[28] Richards EM, Fiskum G, Rosenthal RE, Hopkins I, McKenna MC (2007) Hyperoxic reperfusion after global ischemia decreases hippocampal energy metabolism. Stroke 38, 15781584.

[29] Balan IS, Fiskum G, Hazelton J, Cotto-Cumba C, Rosenthal RE (2006) Oximetry-guided reoxygenation improves neurological outcome after experimental cardiac arrest. Stroke 37, 3008-3013.

[30] Fiskum G, Danilov CA, Mehrabian Z, Bambrick LL, Kristian T, McKenna MC, Hopkins I, Richards EM, Rosenthal RE (2008) Postischemic oxidative stress promotes mitochondrial metabolic failure in neurons and astrocytes. Ann N Y Acad Sci 1147, 129-38.

[31] Allen BW, Demchenko IT, Piantadosi CA (2009) Two faces of nitric oxide: implications for cellular mechanisms of oxygen toxicity. J Appl Physiol 106, 662-667.

[32] Moncada S, Bolanos JP (2006) Nitric oxide, cell bioenergetics and neurodegeneration. J Neurochem 97, 1676-1689.

[33] Kim-Han JS, Dugan LL (2005) Mitochondrial uncoupling proteins in the central nervous system. Antioxid Redox Signal 7, 1173-1181.

[34] Conti B, Sugama S, Lucero J, Winsky-Sommerer R, Wirz SA, Maher P, Andrews Z, Barr AM, Morale MC, Paneda C, Pemberton J, Gaidarova S, Behrens MM, Beal F, Sanna PP, Horvath T, Bartfai T (2005) Uncoupling protein 2 protects dopaminergic neurons from acute 1,2,3,6-methylphenyl-tetrahydropyridine toxicity. $J$ Neurochem 93, 493501.

[35] Sullivan PG, Springer JE, Hall ED, Scheff SW (2004) Mitochondrial uncoupling as a therapeutic target following neuronal injury. J Bioenerg Biomembr 36, 353-356.

[36] Mattiasson G, Shamloo M, Gido G, Mathi K, Tomasevic G, Yi S, Warden CH, Castilho RF, Melcher T, Gonzalez-Zulueta M, Nikolich K, Wieloch T (2003) Uncoupling protein-2 prevents neuronal death and diminishes brain dysfunction after stroke and brain trauma. Nat Med 9, 1062-1068.

[37] Johnson-Cadwell LI, Jekabsons MB, Wang A, Polster BM, Nicholls DG (2007) 'Mild Uncoupling' does not decrease mitochondrial superoxide levels in cultured cerebellar granule neurons but decreases spare respiratory capacity and increases toxicity to glutamate and oxidative stress. $J$ Neurochem 101, 1619-1631.

[38] Chan PH (2005) Mitochondrial dysfunction and oxidative stress as determinants of cell death/survival in stroke. Ann N Y Acad Sci 1042, 203-209.

[39] Esposito L, Raber J, Kekonius L, Yan F, Yu GQ, Bien-Ly N, Puolivali J, Scearce-Levie K, Masliah E, Mucke L (2006) Reduction in mitochondrial superoxide dismutase modulates Alzheimer's disease-like pathology and accelerates the onset of behavioral changes in human amyloid precursor protein transgenic mice. J Neurosci 26, 5167-5179.

[40] Andreassen OA, Ferrante RJ, Dedeoglu A, Albers DW, Klivenyi P, Carlson EJ, Epstein CJ, Beal MF (2001) Mice with a partial deficiency of manganese superoxide dismutase show increased vulnerability to the mitochondrial toxins malonate, 3-nitropropionic acid, and MPTP. Exp Neurol 167, 189-195.

[41] Murakami K, Kondo T, Kawase M, Li Y, Sato S, Chen SF, Chan PH (1998) Mitochondrial susceptibility to oxidative stress exacerbates cerebral infarction that follows permanent focal cerebral ischemia in mutant mice with manganese superoxide dismutase deficiency. J Neurosci 18, 205-213.
[42] Mazzeo AT, Beat A, Singh A, Bullock MR (2009) The role of mitochondrial transition pore, and its modulation, in traumatic brain injury and delayed neurodegeneration after TBI. Exp Neurol 218, 363-370.

[43] Schinzel AC, Takeuchi O, Huang Z, Fisher JK, Zhou Z, Rubens J, Hetz C, Danial NN, Moskowitz MA, Korsmeyer SJ (2005) Cyclophilin D is a component of mitochondrial permeability transition and mediates neuronal cell death after focal cerebral ischemia. Proc Natl Acad Sci U S A 102, 1200512010.

[44] Forte M, Gold BG, Marracci G, Chaudhary P, Basso E, Johnsen D, Yu X, Fowlkes J, Rahder M, Stem K, Bernardi P, Bourdette D (2007) Cyclophilin D inactivation protects axons in experimental autoimmune encephalomyelitis, an animal model of multiple sclerosis. Proc Natl Acad Sci U S A 104, 7558-7563.

[45] Jaiswal AK (2004) Nrf2 signaling in coordinated activation of antioxidant gene expression. Free Radic Biol Med 36, 1199-1207.

[46] Li W, Kong AN (2009) Molecular mechanisms of Nrf2mediated antioxidant response. Mol Carcinog 48, 91-104.

[47] Li W, Yu S, Liu T, Kim JH, Blank V, Li H, Kong AN (2008) Heterodimerization with small Maf proteins enhances nuclear retention of Nrf2 via masking the NESzip motif.Biochim Biophys Acta 1783, 1847-1856.

[48] Yu X, Kensler T (2005) Nrf2 as a target for cancer chemoprevention. Mutat Res 591, 93-102.

[49] Jain AK, Jaiswal AK (2007) GSK-3beta acts upstream of Fyn kinase in regulation of nuclear export and degradation of NF-E2 related factor 2. J Biol Chem 282, 16502-16510.

[50] Thimmulappa RK, Mai KH, Srisuma S, Kensler TW, Yamamoto M, Biswal S (2002) Identification of Nrf2-regulated genes induced by the chemopreventive agent sulforaphane by oligonucleotide microarray. Cancer Res 62, 5196-5203.

[51] Hu R, Xu C, Shen G, Jain MR, Khor TO, Gopalkrishnan A, Lin W, Reddy B, Chan JY, Kong AN (2006) Identification of Nrf2-regulated genes induced by chemopreventive isothiocyanate PEITC by oligonucleotide microarray. Life Sci 79, 1944-1955.

[52] Wattenberg LW, Coccia JB, Lam LK (1980) Inhibitory effects of phenolic compounds on benzo(a)pyrene-induced neoplasia. Cancer Res 40, 2820-2823.

[53] Ramos-Gomez M, Kwak MK, Dolan PM, Itoh K, Yamamoto M, Talalay P, Kensler TW (2001) Sensitivity to carcinogenesis is increased and chemoprotective efficacy of enzyme inducers is lost in nrf2 transcription factor-deficient mice. Proc Natl Acad Sci U S A 98, 3410-3415.

[54] Fahey JW, Talalay P (1999) Antioxidant functions of sulforaphane: a potent inducer of Phase II detoxication enzymes. Food Chem Toxicol 37, 973-979.

[55] Dinkova-Kostova AT, Holtzclaw WD, Cole RN, Itoh K, Wakabayashi N, Katoh Y, Yamamoto M, Talalay P (2002) Direct evidence that sulfhydryl groups of Keap1 are the sensors regulating induction of phase 2 enzymes that protect against carcinogens and oxidants. Proc Natl Acad Sci U S A 99, 11908-11913.

[56] Satoh T, Kosaka K, Itoh K, Kobayashi A, Yamamoto M, Shimojo Y, Kitajima C, Cui J, Kamins J, Okamoto S, Izumi M, Shirasawa T, Lipton SA (2008) Carnosic acid, a catecholtype electrophilic compound, protects neurons both in vitro and in vivo through activation of the Keap1/Nrf2 pathway via S-alkylation of targeted cysteines on Keap1. J Neurochem 104, 1116-1131. 
[57] Pugazhenthi S, Akhov L, Selvaraj G, Wang M, Alam J (2007) Regulation of heme oxygenase-1 expression by demethoxy curcuminoids through Nrf2 by a PI3-kinase/Akt-mediated pathway in mouse beta-cells. Am J Physiol Endocrinol Metab 293, E645-E655.

[58] Gharavi N, Haggarty S, El Kadi AO (2007) Chemoprotective and carcinogenic effects of tert-butylhydroquinone and its metabolites. Curr Drug Metab 8, 1-7.

[59] Son TG, Camandola S, Arumugam TV, Cutler RG, Telljohann RS, Mughal MR, Moore TA, Luo W, Yu QS, Johnson DA, Johnson JA, Greig NH, Mattson MP (2010) Plumbagin, a novel Nrf2/ARE activator, protects against cerebral ischemia. J Neurochem 112, 1316-1326.

[60] Wang L, Chen Y, Sternberg P, Cai J (2008) Essential roles of the PI3 kinase/Akt pathway in regulating Nrf2-dependent antioxidant functions in the RPE. Invest Ophthalmol Vis Sci 49, 1671-1678.

[61] Kaspar JW, Niture SK, Jaiswal AK (2009) Nrf2:INrf2 (Keap1) signaling in oxidative stress. Free Radic Biol Med 47, 1304-1309.

[62] Niture SK, Kaspar JW, Shen J, Jaiswal AK (2009) Nrf2 signaling and cell survival. Toxicol Appl Pharmacol 244, 37-42.

[63] Zhao X, Sun G, Zhang J, Strong R, Dash PK, Kan YW, Grotta JC, Aronowski J (2007) Transcription Factor Nrf2 Protects the Brain From Damage Produced by Intracerebral Hemorrhage. Stroke 38, 3280-3286.

[64] Wang J, Fields J, Zhao C, Langer J, Thimmulappa RK, Kensler TW, Yamamoto M, Biswal S, Dore S (2007) Role of Nrf2 in protection against intracerebral hemorrhage injury in mice. Free Radic Biol Med 43, 408-414.

[65] Zhao J, Kobori N, Aronowski J, Dash PK (2006) Sulforaphane reduces infarct volume following focal cerebral ischemia in rodents. Neurosci Lett 393, 108-112.

[66] Shah ZA, Li RC, Thimmulappa RK, Kensler TW, Yamamoto M, Biswal S, Dore S (2007) Role of reactive oxygen species in modulation of $\mathrm{Nrf} 2$ following ischemic reperfusion injury. Neuroscience 147, 53-59.

[67] Shih AY, Li P, Murphy TH (2005) A small-moleculeinducible Nrf2-mediated antioxidant response provides effective prophylaxis against cerebral ischemia in vivo. $\mathrm{J} \mathrm{Neu-}$ rosci 25, 10321-10335.

[68] Dash PK, Zhao J, Orsi SA, Zhang M, Moore AN (2009) Sulforaphane improves cognitive function administered following traumatic brain injury. Neurosci Lett 460, 103-107.

[69] Zhao J, Moore AN, Clifton GL, Dash PK (2005) Sulforaphane enhances aquaporin-4 expression and decreases cerebral edema following traumatic brain injury. $J$ Neurosci Res 82, 499-506.

[70] Zhao J, Moore AN, Redell JB, Dash PK (2007) Enhancing expression of Nrf2-driven genes protects the blood brain barrier after brain injury. $J$ Neurosci 27, 10240-10248.

[71] Fiskum G, Greco T, Hazelton J, Balan I, Racz J, Cotto-Cumba C, Rosenthal RE (2010) Sulforaphane inhibits redox regulated mitochondrial permeability transition and provides neuroprotection after cardiac arrest. Abstr Am Soc Neurochem Meet, 156.

[72] Soane L, Li DW, Fiskum G, Bambrick LL (2009) Sulforaphane protects immature hippocampal neurons against death caused by exposure to hemin or to oxygen and glucose deprivation. J Neurosci Res 88, 1355-1363.

[73] Danilov CA, Chandrasekaran K, Racz J, Soane L, Zielke C, Fiskum G: Sulforaphane protects astrocytes against oxidative stress and delayed death caused by oxygen and glucose deprivation. Glia 57, 645-656.
[74] Liu XY, Li CY, Bu H, Li Z, Li B, Sun MM, Guo YS, Zhang L, Ren WB, Fan ZL, Wu DX, Wu SY: The neuroprotective potential of phase II enzyme inducer on motor neuron survival in traumatic spinal cord injury in vitro. Cell Mol Neurobiol 28, 769-779.

[75] Eftekharzadeh B, Maghsoudi N, Khodagholi F (2010) Stabilization of transcription factor Nrf2 by tBHQ prevents oxidative stress-induced amyloid beta formation in NT2N neurons. Biochimie 92, 245-253.

[76] Kanninen K, Heikkinen R, Malm T, Rolova T, Kuhmonen S, Leinonen H, Yla-Herttuala S, Tanila H, Levonen AL, Koistinaho M, Koistinaho J (2009) Intrahippocampal injection of a lentiviral vector expressing Nrf2 improves spatial learning in a mouse model of Alzheimer's disease. Proc Natl Acad Sci U S A 106, 16505-16510.

[77] Calkins MJ, Jakel RJ, Johnson DA, Chan K, Kan YW, Johnson JA (2005) Protection from mitochondrial complex II inhibition in vitro and in vivo by Nrf2-mediated transcription. Proc Natl Acad Sci U S A 102, 244-249.

[78] Siebert A, Desai V, Chandrasekaran K, Fiskum G, Jafri MS (2009) Nrf2 activators provide neuroprotection against 6hydroxydopamine toxicity in rat organotypic nigrostriatal cocultures. J Neurosci Res 87, 1659-1669.

[79] Tarozzi A, Morroni F, Merlicco A, Hrelia S, Angeloni C, Cantelli-Forti G, Hrelia P (2009) Sulforaphane as an inducer of glutathione prevents oxidative stress-induced cell death in a dopaminergic-like neuroblastoma cell line. J Neurochem 111, 1161-1171.

[80] Chen PC, Vargas MR, Pani AK, Smeyne RJ, Johnson DA, Kan YW, Johnson JA (2009) Nrf2-mediated neuroprotection in the MPTP mouse model of Parkinson's disease: Critical role for the astrocyte. Proc Natl Acad Sci U S A 106, 29332938.

[81] Vargas MR, Johnson DA, Sirkis DW, Messing A, Johnson JA (2008) Nrf2 activation in astrocytes protects against neurodegeneration in mouse models of familial amyotrophic lateral sclerosis. J Neurosci 28, 13574-13581.

[82] Burton NC, Kensler TW, Guilarte TR (2006) In vivo modulation of the Parkinsonian phenotype by Nrf2. Neurotoxicology 27, 1094-1100.

[83] Kraft AD, Lee JM, Johnson DA, Kan YW, Johnson JA (2006) Neuronal sensitivity to kainic acid is dependent on the Nrf2mediated actions of the antioxidant response element. $\mathrm{J} \mathrm{Neu}$ rochem $\mathbf{9 8}, 1852-1865$.

[84] Nimura T, Weinstein PR, Massa SM, Panter S, Sharp FR (1996) Heme oxygenase-1 (HO-1) protein induction in rat brain following focal ischemia. Mol Brain Res 37, 201-208.

[85] Mattson MP (1997) Neuroprotective signal transduction: relevance to stroke. Neurosci Biobehav Rev 21, 193-206.

[86] Shukla PK, Khanna VK, Ali MM, Khan MY, Srimal RC (2008) Anti-ischemic effect of curcumin in rat brain. Neurochem Res 33, 1036-1043.

[87] Valdivia A, Perez-Alvarez S, roca-Aguilar JD, Ikuta I, Jordan J (2009) Superoxide dismutases: a physiopharmacological update. J Physiol Biochem 65, 195-208.

[88] Dohare P, Garg P, Jain V, Nath C, Ray M (2008) Dose dependence and therapeutic window for the neuroprotective effects of curcumin in thromboembolic model of rat. Behav Brain Res 193, 289-297.

[89] Al-Omar FA, Nagi MN, Abdulgadir MM, Al Joni KS, Al-Majed AA (2006) Immediate and delayed treatments with curcumin prevents forebrain ischemia-induced neuronal damage and oxidative insult in the rat hippocampus. Neurochem Res 31, 611-618. 
[90] Dringen R, Pawlowski PG, Hirrlinger J (2005) Peroxide detoxification by brain cells. J Neurosci Res 79, 157-165.

[91] Lavoie S, Chen Y, Dalton TP, Gysin R, Cuenod M, Steullet P, Do KQ (2009) Curcumin, quercetin, and tBHQ modulate glutathione levels in astrocytes and neurons: importance of the glutamate cysteine ligase modifier subunit. J Neurochem 108, 1410-1422.

[92] Piantadosi CA, Carraway MS, Babiker A, Suliman HB (2008) Heme oxygenase-1 regulates cardiac mitochondrial biogenesis via Nrf2-mediated transcriptional control of nuclear respiratory factor-1. Circ Res 103, 1232-1240.

[93] Lee JM, Calkins MJ, Chan K, Kan YW, Johnson JA (2003) Identification of the NF-E2-related factor-2-dependent genes conferring protection against oxidative stress in primary cortical astrocytes using oligonucleotide microarray analysis. $J$ Biol Chem 278, 12029-12038.

[94] Lambert AJ, Brand MD (2009) Reactive oxygen species production by mitochondria. Methods Mol Biol 554, 16581.:165-181.

[95] Stowe DF, Camara AK (2009) Mitochondrial reactive oxygen species production in excitable cells: modulators of mitochondrial and cell function. Antioxid Redox Signal 11, 13731414.

[96] Murphy MP (2009) How mitochondria produce reactive oxygen species. Biochem J 417, 1-13.

[97] Starkov AA (2008) The role of mitochondria in reactive oxygen species metabolism and signaling. Ann N Y Acad Sci 1147, 37-52.

[98] Starkov AA, Fiskum G, Chinopoulos C, Lorenzo BJ, Browne SE, Patel MS, Beal MF (2004) Mitochondrial alpha-ketoglutarate dehydrogenase complex generates reactive oxygen species. J Neurosci 24, 7779-7788.

[99] Tretter L, Adam-Vizi V (2004) Generation of reactive oxygen species in the reaction catalyzed by alpha-ketoglutarate dehydrogenase. J Neurosci 24, 7771-7778.

[100] Alves E, Summavielle T, Alves CJ, Gomes-da-Silva J, Barata JC, Fernandes E, Bastos ML, Tavares MA, Carvalho F (2007) Monoamine oxidase-B mediates ecstasy-induced neurotoxic effects to adolescent rat brain mitochondria. J Neurosci 27, 10203-10210.

[101] Sinet PM, Heikkila RE, Cohen G (1980) Hydrogen peroxide production by rat brain in vivo. J Neurochem 34, 1421-1428.

[102] Hogberg J, Orrenius S, Larson RE (1975) Lipid peroxidation in isolated hepatocytes. Eur J Biochem 50, 595-602.

[103] Zhu H, Jia Z, Strobl JS, Ehrich M, Misra HP, Li Y (2008) Potent induction of total cellular and mitochondrial antioxidants and phase 2 enzymes by cruciferous sulforaphane in rat aortic smooth muscle cells: cytoprotection against oxidative and electrophilic stress. Cardiovasc Toxicol 8, 115-125.

[104] Zhu H, Jia Z, Zhou K, Misra H, Santo A, Gabrielson KL, Li Y (2009) Cruciferous dithiolethione-mediated coordinated induction of total cellular and mitochondrial antioxidants and phase 2 enzymes in human primary cardiomyocytes: cytoprotection against oxidative/electrophilic stress and doxorubicin toxicity. Exp Biol Med (Maywood) 234, 418-429.

[105] Fiskum G, Pease A (1986) Hydroperoxide-stimulated release of calcium from rat liver and AS-30D hepatoma mitochondria. Cancer Res 46, 3459-3463.

[106] Mukherjee S, Gangopadhyay H, Das DK (2008) Broccoli: a unique vegetable that protects mammalian hearts through the redox cycling of the thioredoxin superfamily. J Agric Food Chem 56, 609-617.

[107] Kowaltowski AJ, Vercesi AE, Fiskum G (2000) Bcl-2 prevents mitochondrial permeability transition and cytochrome c release via maintenance of reduced pyridine nucleotides. Cell Death Differ 7, 903-910.

[108] Robertson CL, Scafidi S, McKenna MC, Fiskum G (2009) Mitochondrial mechanisms of cell death and neuroprotection in pediatric ischemic and traumatic brain injury. Exp Neurol 218, 371-380.

[109] Halestrap AP (2009) Mitochondria and reperfusion injury of the heart - a holey death but not beyond salvation. J Bioenerg Biomembr 41, 113-121.

[110] Bernardi P, Rasola A (2007) Calcium and cell death: the mitochondrial connection. Subcell Biochem 45, 481-506. 